\title{
The chloride requirement for photosynthetic oxygen evolution: factors affecting nucleophilic displacement of chloride from the oxygen-evolving complex
}

\author{
P.O. Sandusky * and C.F. Yocum ** \\ Division of Biological Sciences and Department of Chemistry, University of Michigan, Ann Arbor, MI 48109 (U.S.A.)
}

(Received September 30th, 1985)

(Revised manuscript received December 20th, 1985)

Key words: Photosystem II; Oxygen evolution; Amine inhibition; $\mathrm{Cl}^{-}$effect; Photosynthesis; (Spinach chloroplast)

Previous research (Sandusky, P.O. and Yocum, C.F. (1983) FEBS Lett. 162, 339-343 and (1984) Biochim. Biophys. Acta 766, 603-611) has documented a competition between chloride and ammonia or Tris for a binding site within the oxygen-evolving complex of Photosystem II. This competition is in fact a general property of inhibitory amines which is related to their nucleophilicity; this in turn suggests that the binding site is associated with a metal. Only ammonia, of all amines tested, is able to occupy a second binding site which is unrelated to the site of chloride binding; this sterically hindered site may be identical to the site already described for binding of hydroxylamine, hydrazine, and certain of their derivatives (Radmer, $R$. and Ollinger, O. (1983) FEBS Lett. 152, 39-43). When the interaction between amines, chloride and the inhibitory halide fluoride was examined, steady-state kinetic plotting procedures revealed that amines and fluoride compete for the chloride binding site; binding of one inhibitor precludes the binding of the other. It was also observed that the intensity of inhibitor binding to the oxygen-evolving complex was influenced by the electron acceptor present during assays; stronger inhibition was observed with a PS II-specific electron acceptor (2,5-dichloro-p-benzoquinone) than with an acceptor (ferricyanide) which requires electron transport to the reducing terminus of Photosystem $I$. These results are interpreted in terms of a model which proposes that the binding site for chloride on the oxidizing side of Photosystem II resides within the pool of functional manganese associated with the oxygen-evolving complex of Photosystem II.

\section{Introduction}

Based on work in the laboratories of Arnon et al. $[1,2]$ and Izawa et al. $[3,4]$, it has been known for some time that the presence of chloride activates the oxygen-evolving complex of PS II.

\footnotetext{
* Present address: Department of Chemistry, Stanford University, Stanford, CA 94305, U.S.A.

** To whom correspondence should be addressed.

Abbreviations: Hepes, 4-(2-hydroxyethyl)-1-piperazineethanesulfonic acid; AEPD, 2-amino-2-ethylpropanediol; DCBQ, 2,5-dichloro-p-benzoquinone; PS, Photosystem, Chl, chlorophyll; Mes, 4-morpholineethanesulfonic acid.
}

This has been recently confirmed by the experiments of Itoh et al. [5] and Theg et al. [6] which showed that chloride depletion creates a lesion in electron transport between the oxygen-evolving site and $\mathrm{Z}$, the primary donor to $\mathrm{P}-680^{+}$. A limited number of other anions, specifically bromide, iodide and nitrate, can substitute for chloride in supporting oxygen evolution, but the chemical mechanism by which chloride and these other anions activate the oxygen-evolving apparatus remains unclear at this time, and two hypotheses have been proposed. Homann has suggested that chloride binds to positively charged protein moie- 
ties, possibly protonated lysine residues, and functions by stabilizing an active conformation of the oxygen-evolving complex $[7,8]$. Alternatively, Bové et al. [2], Wydryzynsky and Sauer [9] and, more recently, we $[10,11]$ have proposed that chloride might bind as a ligand to the functional pool of manganese which is involved as a cofactor in the oxygen-evolving reaction [12]. A variant on the second hypothesis is the suggestion that chloride binds as ligand bridging between $\mathrm{Mn}$ atoms to mediate electron transport. This possibility was originally suggested by Bové et al. [2] and has more recently been discussed by us [10,11] (see also Refs. 13 and 14).

In contrast to activation by chloride, several amines induce a reversible inhibition of the oxygen-evolving complex, and it has been concluded that these amine inhibitors bind in their free base forms to the $S_{2}$ and $S_{3}$ states of the oxygen-evolving complex [15-17]. These results have been interpreted to indicate that amines bind as inhibitors to ligand sites on redox active manganese; recent chemical, ESR, optical and Xray absorption edge results all indicate that manganese in the oxygen-evolving complex is in fact redox active [18-21].

The fact that one group of nucleophiles, chloride and the chloride surrogate anions, activates the oxygen-evolving apparatus, whereas another group of nucleophiles, the free-base species of various amines, inhibits the system, suggested to us that both groups might bind to the same electrophilic site. We have previously reported the results of steady-state kinetic experiments which support this hypothesis $[10,11]$. Those data demonstrated that inhibitory Tris binding was purely competitive with chloride, whereas ammonia-induced inhibition involved binding at two sites, only one of which was competitive with chloride. In this communication, we present evidence to support the hypothesis that amines and halides can occupy the same electrophilic binding site in the oxygen-evolving complex. In order to determine the effects of amine size and $\mathrm{p} K_{\mathrm{a}}$ on amine-induced inhibition we have carried out amine/chloride competition experiments employing a variety of amines. In addition, in order to investigate whether charge neutralization is involved in anion activation of oxygen-evolution activity, we have studied the inhibitory properties of fluoride. In the course of this research we observed that the presence of a class III electron acceptor (DCBQ) enhances the inhibition of activity produced by amines and fluoride. We propose that this enhanced inhibition in the presence of DCBQ may be related to preferential inhibitor binding to the higher $\mathrm{S}$ states.

\section{Materials and Methods}

Chloroplast thylakoid membranes were isolated from market spinach as previously described [22]. Oxygen-evolving PS II-enriched membranes were prepared by the method of Berthold et al. [23] with the modifications described in Ref. 24. Photosystem II-enriched membranes were used in experiments which assayed competition between nonphysiological anions (fluoride, acetate) and a physiological anion (chloride) or a permeant nucleophile (amine free bases), so that possible permeability barriers to non-physiological anions, imposed by intact thylakoid membranes, would not influence the results. Stock solutions of amines were adjusted to the desired $\mathrm{pH}$ with Hepes and $\mathrm{NaOH}$. All reagents were prepared so as to minimize chloride contamination. Measurements of oxygen-evolution activity were carried out using a thermostatted $\left(25^{\circ} \mathrm{C}\right)$ Clark-type electrode [25]; saturating light was provided by two high-intensity microscope illuminators. The assay conditions varied from experiment to experiment and are described in the figure legends.

\section{Results}

Effect of amine size and $p K_{a}$ on amine-induced inhibition of the oxygen-evolving complex

Previously, we used steady-state kinetics to show that Tris binds competitively with chloride, whereas ammonia is a mixed inhibitor which binds both competitively and noncompetitively with respect to chloride $[10,11]$. Chemically, ammonia differs from Tris in two respects; it is smaller than Tris and it is a stronger nucleophile (Tris and ammonia have $\mathrm{p} K_{\mathrm{a}}$ values of 8 and 9.2, respectively.) In order to assess which of these properties, size or nucleophilicity, is responsible for the difference between the inhibitory effects of Tris and am- 
monia, we repeated the amine/chloride experiments with amines of varying size and $\mathrm{p} K_{\mathrm{a}}$ (2amino-2-ethylpropanediol, $t$-butylamine and methylamine). The results of these experiments were analyzed using the plotting procedure described by Cornish-Bowden [26,27]. In this procedure, the dissociation constant of the enzyme-inhibitor complex $\left(K_{\mathrm{i}}\right)$ is given by the negative abscissa intersection point on a Dixon plot $(1 / v$ vs. inhibitor concentration); the dissociation constant of the enzyme-inhibitor-activator complex $\left(K_{\mathrm{i}}^{\prime}\right)$ can be estimated from the intersection point on a Cornish-Bowden plot (activator $/ v$ vs. inhibitor concentration). Competitive binding of inhibitor and activator will result in a set of intersecting lines on a Dixon plot, and nearly parallel lines on a Cornish-Bowden plot (these results are indicative of relatively small $K_{\mathrm{i}}$ and relatively large $K_{\mathrm{i}}^{\prime}$ values). We have found this method to be more useful for our purposes than the more widely used Lineweaver-Burk procedure; it is often difficult to distinguish competitive and mixed modes of inhibition using the $1 / v$ vs. $1 /$ activator plot.

The results of the Dixon/Cornish-Bowden plot analysis indicate that, with the single exception of ammonia, all of the amines we have studied bind as inhibitors only in competition with chloride. The results of a typical experiment using : $t$ butylamine are shown in Fig. 1. These rsults are representative of the other amine/chloride experiments. A comparison of the $K_{\mathrm{i}}$ and $K_{\mathrm{i}}^{\prime}$ values for the various amines is shown in Table $I$. Two of the amines, $t$-butylamine and methylamine, have $\mathrm{p} K_{\mathrm{a}}$ values almost two orders of magnitude higher than ammonia. The data of Table I $\left(K_{\mathrm{i}}^{\prime} / K_{\mathrm{i}}\right.$ values) show that substituted amines have a lowered affinity for the chloride-insensitive site when compared to ammonia; a comparison of AEPD $\left(\mathrm{p} K_{\mathrm{a}}=9.0\right)$ with ammonia $\left(\mathrm{p} K_{\mathrm{a}}=9.2\right)$ provides a convenient demonstration that size, rather than nucleophilicity, is the factor governing the interaction of amines with the second, chloride-insensitive site in the oxygen-evolving complex. This supports our initial hypothesis that ammonia binds to two inhibitor sites (or perhaps two classes of sites), only one of which is the chloride-binding site [11]. The larger amines must be exoluded from the second ammonia binding site due to their size. We have suggested that this second, sterically hindered site of ammonia inhibition may be the water-oxidizing site itself. This observation is in accord with the suggestion by Radmer that the $\mathrm{H}_{2} \mathrm{O}$ binding site resides in a cleft in the oxygen-evolving complex from which bulky substates are excluded [28].

The binding properties of ligands to a metal are sometimes determined by ligand basicity [30]. Often, when studying the binding of a particular metal ion by a homologous 'family' of ligands, such as a group of aromatic carboxylates or a group of primary aliphatic amines, the plot of the negative logarithm of the dissociation constant of the metal-ligand complex vs. the ligand $\mathrm{p} K_{\mathrm{a}}$ forms a straight line. In this situation, the ligands view the metal as a proton of unusually large size and charge. If the hypothesis that amines and chloride compete for a ligand site on manganese in the

\section{TABLE 1}

\section{$K_{\mathrm{i}}$ AND $K_{\mathrm{i}}^{\prime}$ VALUES DERIVED FROM STEADY STATE KINETIC EXPERIMENTS}

$K_{\mathrm{i}}$ values were taken from the intersections of Dixon plots. With the exception of the ammonia plot, the lines of the Cornish-Bowden plots did not intersect at one point. Therefore, the $K_{\mathrm{i}}^{\prime}$ values presented are the average values of the various intersection points. The $K_{\mathrm{i}}$ and $K_{\mathrm{i}}^{\prime}$ values are given in the millimolar quantities which have been corrected using the amine $\mathrm{p} K_{\mathrm{a}}$ values [29] so as to refer to the dissociation constants of the amine-free base-oxygen-evolving complex and amine-free base-oxygen-evolving complex -chloride complexes, respectively. The uncertainties in the $K_{\mathrm{i}}$ values were estimated based on the statistical uncertainties of the Dixon plot least square lines.

\begin{tabular}{lcccc}
\hline Amine inhibitor & $\mathrm{p} K_{\mathrm{a}}\left(25^{\circ} \mathrm{C}\right)$ & $K_{\mathrm{i}}(\mathrm{mM})$ & $K_{\mathrm{i}}^{\prime}(\mathrm{mM})$ & $K_{\mathrm{i}}^{\prime} / K_{\mathrm{i}}$ \\
\hline Tris & 8.0 & $14 \pm 9$ & 355 & 25 \\
AEPD & 9.0 & $0.8 \pm 0.2$ & 20 & 25 \\
Ammonia & 9.2 & $0.39 \pm 0.02$ & $0.53 \pm 0.01$ & 1.4 \\
Methylamine & 10.6 & $0.02 \pm 0.01$ & 0.7 & 35 \\
$t$-Butylamine & 10.7 & $0.03 \pm 0.01$ & 0.3 & 10 \\
\hline
\end{tabular}


oxygen-evolving complex is correct, it might be expected that the binding affinity of various inhibitory amines would increase with amine basicity, and that a plot of the negative logarithms of the $K_{\mathrm{i}}$ values derived from the Dixon plot intersections, plotted against the negative logarithms of the amine $K_{\mathrm{a}}$ values, would form a straight line. This is in fact the case, as shown in Fig. 2. Similar

\section{A}

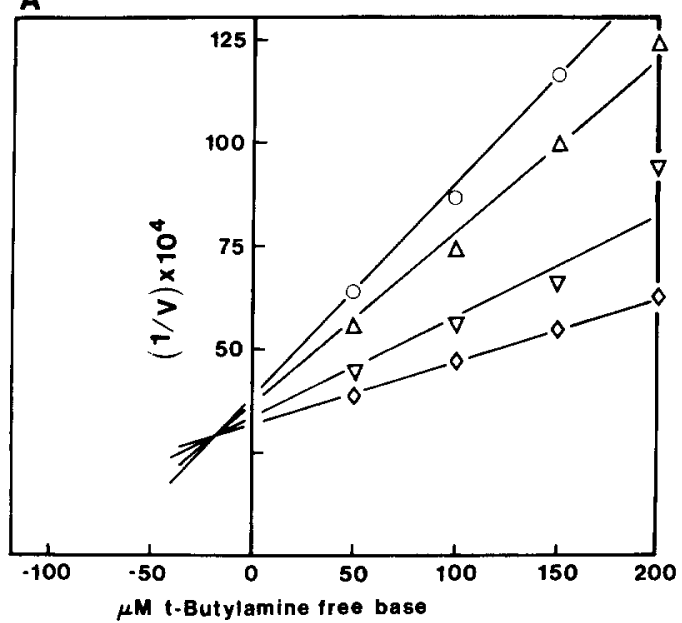

B

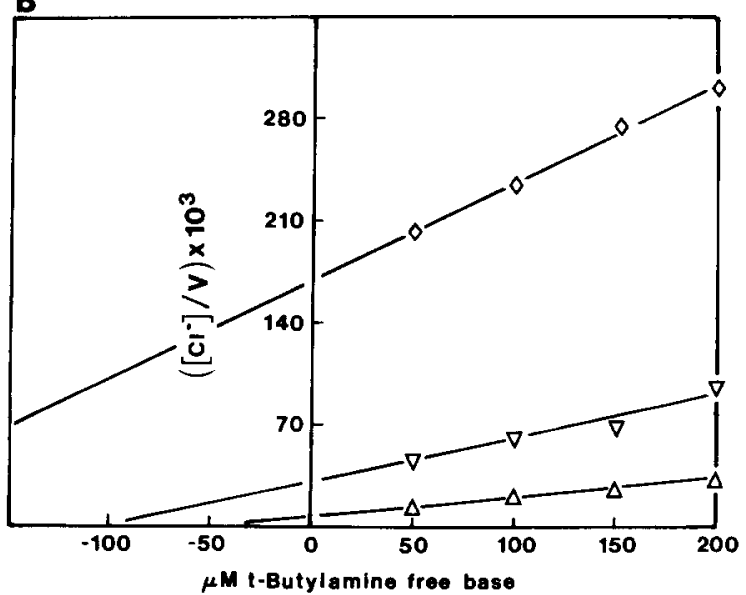

Fig. 1. Inhibitory binding of $t$-butylamine in competition with chloride. The assay medium contained $50 \mathrm{mM}$ Hepes ( $\mathrm{pH} 8$ ); $t$-butylamine was introduced from a solution neutralized with 1 $M$ acidic Hepes, and adjusted to $\mathrm{pH} 8$ with $\mathrm{NaOH}$. Thylakoid membranes were incubated at a Chl concentration of $20 \mu \mathrm{g} \mathrm{per}$ $\mathrm{ml}$ in the amine and buffer for $30 \mathrm{~s}$ before assay; $250 \mu \mathrm{M}$ DCBQ and $2.5 \mathrm{mM} \mathrm{Fe}(\mathrm{CN})_{6}^{-3}$ were added $10 \mathrm{~s}$ before the assay. The points shown here are the average of five experiments (10 assays per point). $0.4 \mathrm{mM}$ chloride $(O) ; 2.4 \mathrm{mM}$ chloride $(\Delta) ; 10.4 \mathrm{mM}$ chloride $(\nabla)$; and $50.4 \mathrm{mM}$ chloride $(\diamond)$. A, Dixon plot; B, Cornish-Bowden plot. results have been reported by Ghanotakis et al. [17], but our experiments differ in that they evaluate the amine $K_{\mathrm{i}}$ values under conditions of controlled chloride concentration.

Interaction of inhibitory anions with the oxygenevolving complex

Anion activation of oxygen-evolution activity is specific insofar as bromide, iodide, and nitrate can replace chloride with varying degrees of effectiveness $[1,2,4]$. Other anions, such as fluoride, sulfate and phosphate, do not support activity. However, it is not clear from earlier research why this second set of anions is ineffective. In the case of fluoride, for instance, it is possible that this anion binds to the chloride site without activating the oxygenevolving complex, or that fluoride binds to the chloride site and activates, while at the same time inducing a secondary inhibition unrelated to anion activation. It is also possible that fluoride does not bind to the chloride site at all. Baianu et al. [31] have reported NMR results indicating that fluoride displaces chloride from binding sites in thylakoid membranes; however, the relationship of this effect to anion activation of the oxygen-evolution activity was not firmly established. Since our earlier results showed that amines and chloride

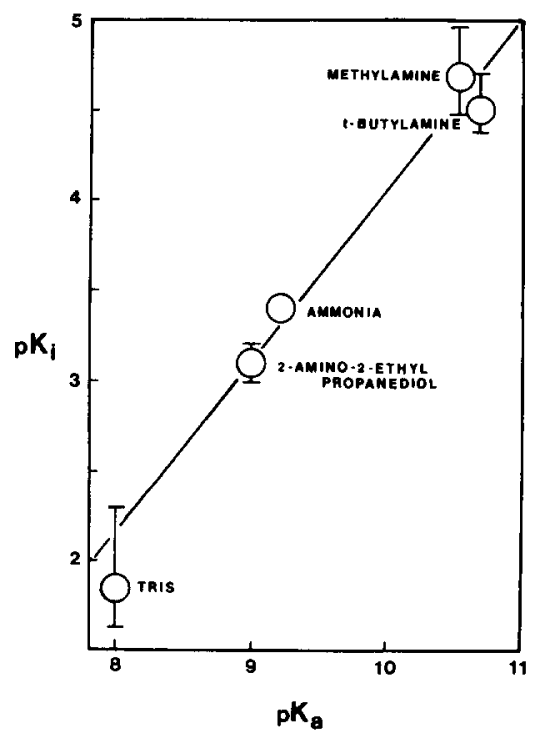

Fig. 2. $\mathrm{p} K_{\mathrm{i}}$ vs. $\mathrm{p} K_{\mathrm{a}}$ plot derived from amine/chloride steadystate kinetic experiments with thylakoid membranes. $K_{\mathrm{i}}$ and $K_{\mathrm{a}}$ values can be found in Table $I$. 
bind competitively, we undertook experiments to determine whether fluoride and other anions bind as inhibitors in competition with chloride, whether there are any modes of fluoride inhibition unrelated to chloride binding, and whether fluoride binding as an inhibitor excludes inhibitory amine binding.

Fluoride and acetate induce inhibitions of oxygen evolution, as indicated in Table II. These inhibitions are attenuated by chloride, bromide, and to a lesser extent by nitrate; data for chloride are shown in Table II. These experiments were conducted in $1 \mathrm{M}$ Hepes at pH 7.6; consequently, the variations in salt concentrations involved in these experiments entailed only small changes in the reaction medium ionic strength. Under these same conditions sulfate does not induce inhibition, nor does it attenuate the inhibitions induced by acetate or fluoride (data not shown). Experiments in which PS II-enriched membranes were dialyzed against $0.4 \mathrm{M}$ sucrose/50 mM Mes (pH 6)/50 $\mathrm{mM} \mathrm{NaF}$ produced a $75 \%$ inhibition relative to membranes dialyzed against sucrose and Mes (data not shown). This inhibition, induced by dialysis against fluoride, is completely reversed by the inclusion of chloride in the assay medium; we would therefore conclude that inhibition induced by the presence of fluoride in the assay medium is also reversible. Inhibitory fluoride binding is

\section{TABLE II}

\section{EFFECT OF CHLORIDE ON INHIBITION OF OXYGEN EVOLUTION ACTIVITY BY FLUORIDE AND ACETATE}

Control activities in the PS II-enriched membranes (with DCBQ as the acceptor) were 230 and $350 \mu \mathrm{mol} \mathrm{O}_{2}$ per $\mathrm{mg} \mathrm{Chl} \mathrm{per} \mathrm{h}$ in the presence of 0.4 and $20.4 \mathrm{mM}$ chloride, respectively. Samples were incubated with the anions for $30 \mathrm{~s}$ in the dark before assay.

\begin{tabular}{lll}
\hline $\begin{array}{l}\text { Anion added } \\
\text { (mM) }\end{array}$ & Activity (\%) & \\
\cline { 2 - 3 } & $0.4 \mathrm{mM} \mathrm{Cl}^{-}$ & $+20.4 \mathrm{mM} \mathrm{Cl}^{-}$ \\
\hline Fluoride & 100 & 100 \\
0 & 70 & 85 \\
20 & 45 & 76 \\
40 & & \\
Acetate & 100 & 100 \\
0 & 78 & 96 \\
20 & 65 & 84 \\
40 & & \\
\hline
\end{tabular}

competitive with chloride binding (Fig. 3). At the fluoride concentrations used in these experiments (up to $40 \mathrm{mM}$ ) there are no detectable secondary modes of fluoride-induced inhibition unrelated to the binding of chloride.

In the case of two inhibitors $\left(I_{1}\right.$ and $\left.I_{2}\right)$ it is possible to use a modified Dixon plot to distinguish whether the binding of one inhibitor is

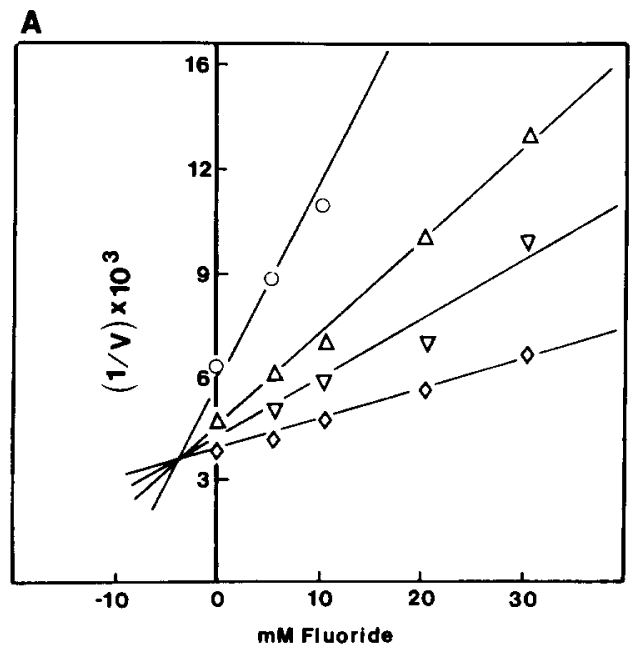

B

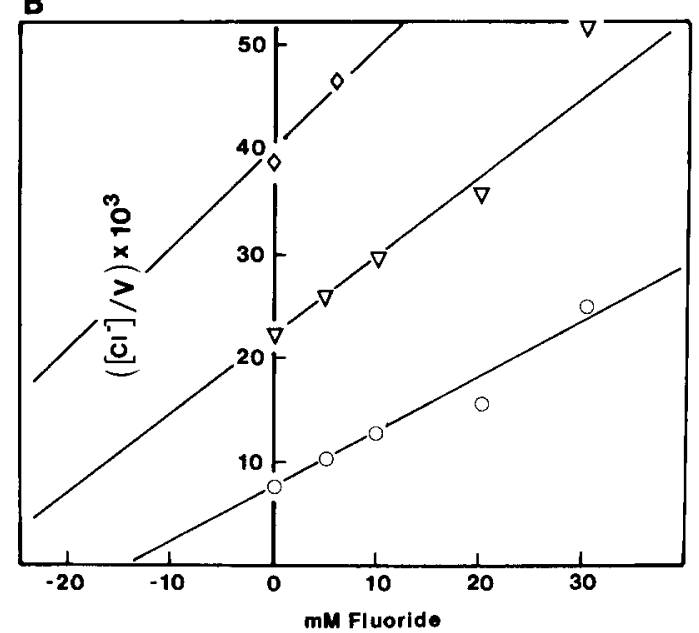

Fig. 3. Fluoride is an inhibitor of oxygen evolution in competition with chloride. The reaction medium contained $50 \mathrm{mM}$ Hepes (pH 7.5). Photosystem Il-enriched membranes (40 $\mu \mathrm{g}$ $\mathrm{Chl} / \mathrm{ml}$ ) were incubated in the reaction medium with fluoride for $1 \mathrm{~min}$ before assay; $250 \mu \mathrm{M}$ DCBQ was added $10 \mathrm{~s}$ prior to assay. The results shown here are the average of four experiments (eight assays per point). $1 \mathrm{~mm}$ chloride (O); $2.5 \mathrm{mM}$ chloride $(\Delta) ; 5 \mathrm{mM}$ chloride $(\nabla) ; 10 \mathrm{mM}$ chloride $(\diamond)$. A, Dixon plot; B, Cornish-Bowden plot. 


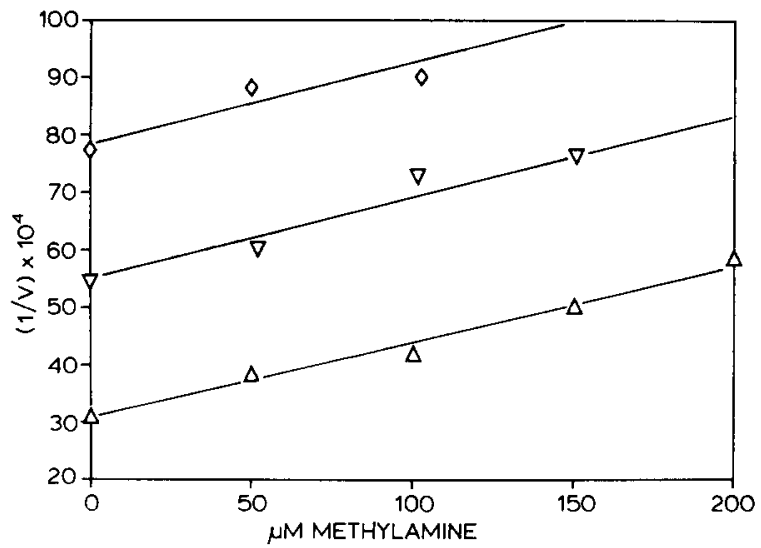

Fig. 4. Modified Dixon plot demonstrating that the binding of fluoride as an inhibitor excludes the inhibitory binding of methylamine. All assays contained $2.5 \mathrm{mM}$ chloride. In other respects assays were performed as described in the legend of Table II. Results are the average of two experiments (four assays per point). No fluoride $(\Delta) ; 20 \mathrm{mM}$ fluoride $(\nabla), 40 \mathrm{mM}$ fluoride $(\diamond)$.

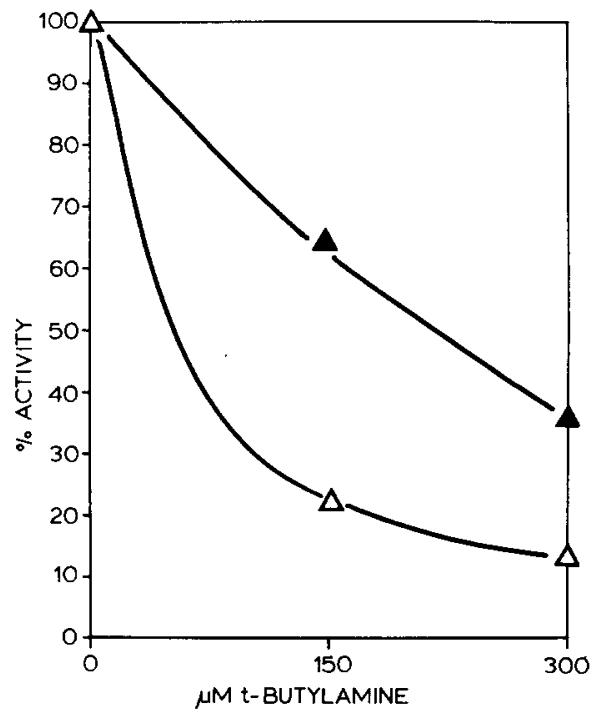

Fig. 5. $t$-Butylamine is a more effective inhibitor when DCBQ is present as an electron acceptor. The reaction medium contained $50 \mathrm{mM}$ Tricine ( $\mathrm{pH} \mathrm{8)} / 0.4 \mathrm{mM}$ chloride. Thylakoid membranes were incubated in the reaction medium with the amine present at a Chl concentration of $20 \mu \mathrm{g}$ per ml for $1 \mathrm{~min}$ before assay; $2.5 \mathrm{mM}$ ferricyanide or $250 \mu \mathrm{M}$ DCBQ was added $10 \mathrm{~s}$ prior to assay; $10 \mu \mathrm{g}$ per $\mathrm{ml}$ gramicidin was also present in the ferricyanide-supported assays. The results shown here are the average of three experiments (six assays per point). The abscissa shows the free base concentration of $t$-butylamine. Control rates were 320 and $270 \mu$ moles oxygen per $\mathrm{mg} \mathrm{Chl}$ per $h$ for the DCBQ and ferricyanide-supported reactions, respectively. $\mathrm{H}_{2} \mathrm{O} \rightarrow$ DCBQ $(\Delta) ; \mathrm{H}_{2} \mathrm{O} \rightarrow$ ferricyanide ( $\Delta$ ). competitive with the binding of the other [27]. Specifically, a plot of $1 / v$ vs. $\mathrm{I}_{1}$ concentration at various concentrations of $I_{2}$ will generate a system of parallel lines if $I_{1}$ and $I_{2}$ bind competitively (Eqn. 1); this plot will result in a set of converging lines if the binding of $I_{1}$ and $I_{2}$ is mixed or noncompetitive (Eqn. 2). (In these experiments the activator concentration ( $\mathrm{A}$, in this case chloride) would be held constant, and $K_{\mathrm{A}}$ is the dissociation constant of $A$ ):

$$
\begin{aligned}
& \frac{1}{V}=\frac{K_{\mathrm{A}}}{[A] V m K_{1}}\left[I_{1}\right]+\frac{1}{V m}\left(1+\frac{K_{\mathrm{A}}}{[A]}+\frac{K_{\mathrm{A}}\left[I_{2}\right]}{[A] K_{2}}\right) \\
& \frac{1}{V}=\frac{K_{\mathrm{A}}}{[A] V m K_{1}}\left(1+\frac{\left[I_{2}\right]}{K_{2}}\right)\left[I_{1}\right]+\frac{1}{V m}\left(1+\frac{K_{\mathrm{A}}}{[A]}+\frac{K_{\mathrm{A}}\left[I_{2}\right]}{[A] K_{2}}\right)
\end{aligned}
$$

The results from experiments using this approach

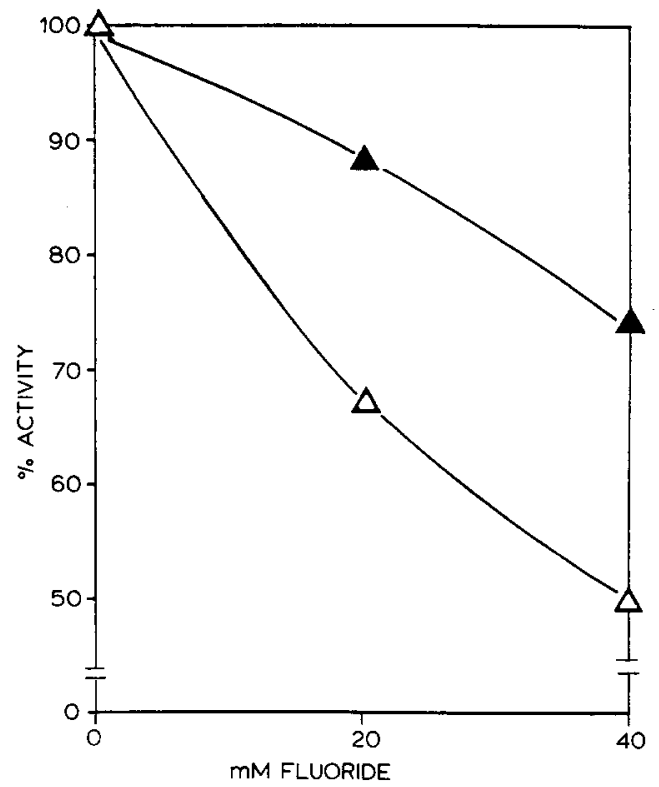

Fig. 6. Fluoride is a more effective inhibitor of oxygen evolution in the presence of DCBQ. The assay medium contained $200 \mathrm{mM}$ Hepes ( $\mathrm{pH} 8$ ) and $10 \mu \mathrm{g}$ per ml gramicidin. Thylakoid membranes were incubated in the reaction medium of Fig. $S$ with fluoride at a Chl concentration of $30 \mu \mathrm{g}$ per $\mathrm{ml}$ for $30 \mathrm{~s}$ before assay; $2.5 \mathrm{mM}$ ferricyanide or $250 \mu \mathrm{M}$ DCBQ were added $10 \mathrm{~s}$ prior to assay. Uninhibited rates were 300 and 180 $\mu$ mol oxygen mg Chl per $h$ for the DCBQ- and ferricyanidesupported reactions, respectively. The results shown here are the average of two experiments (four assays per point). $\mathrm{H}_{2} \mathrm{O} \rightarrow$ DCBQ ( $\triangle$ ); $\mathrm{H}_{2} \mathrm{O} \rightarrow$ ferricyanide ( $\Delta$ ). 
show that the binding of fluoride as an inhibitor of oxygen evolution activity is competitive with inhibitory amine binding. This is shown in Fig. 4 for the case of methylamine. Similar results were obtained with Tris and $t$-butylamine.

Dependence of amine- and fluoride-induced inhibitions on electron acceptors

In the course of the experiments described above it was found that amines and fluoride were more effective inhibitors of oxygen evolution when the class III electron acceptor DCBQ was present in the reaction medium. Fig. 5 compares the inhibitions produced by $t$-butylamine in the presence of either DCBQ or $\mathrm{Fe}(\mathrm{CN})_{6}^{-3}$ as the electron acceptor. In these experiments using intact thylakoid membranes, ferricyanide reduction is DBMIB sensitive (indicating that PS $I$ is the site of photoreduction) whereas $D C B Q$ reduction is insensitive to DBMIB, indicating that DCBQ reacts at the reducing side of PS II. Similar results were obtained using Tris, methylamine and fluoride as the inhibitory reagents (Fig. 6 presents data for fluoride). It is important to note that inhibitions observed with

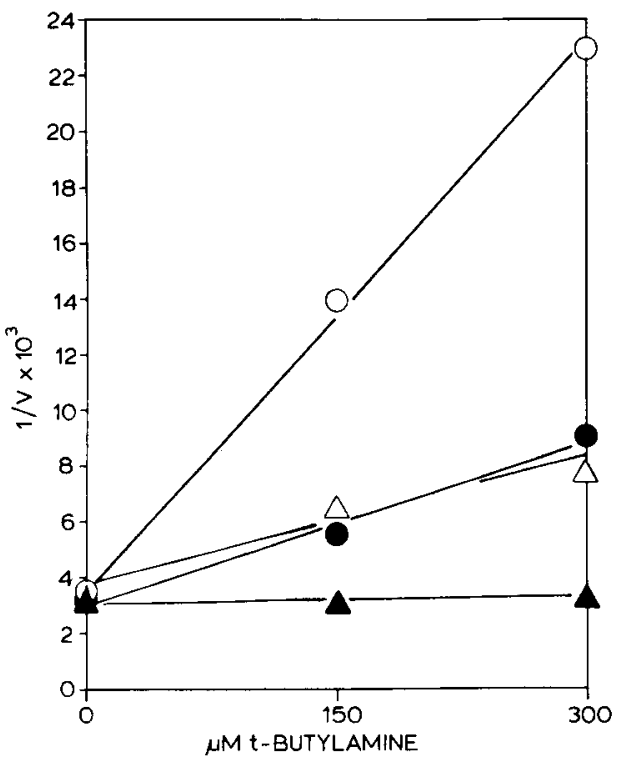

Fig. 7. Effect of DCBQ on the $t$-butylamine $K_{\mathrm{i}}$ value as measured from Dixon plot intersection points. Assays were performed as described in Fig. 5. $\mathrm{H}_{2} \mathrm{O} \rightarrow \mathrm{DCBQ} ; 0.4 \mathrm{mM}$ Chloride (O), $50.4 \mathrm{mM}$ Chloride $(\bullet), \mathrm{H}_{2} \mathrm{O} \rightarrow$ ferricyanide; 0.4 mM Chloride $(\Delta), 50.4 \mathrm{mM}$ Chloride $(\Delta)$.
DCBQ alone are as effective as those obtained in the presence of $\mathrm{DCBQ}$ and $\mathrm{Fe}(\mathrm{CN})_{6}^{-3}$ together (compare Fig. 5 to Fig. 1). Further, it should be stressed that regardless of the electron acceptor system used, the inhibitors still bind competitively with chloride; only the inhibitor dissociation constant $\left(K_{\mathrm{i}}\right)$ is lowered when DCBQ is present (Fig. $7)$ as an explanation for the electron acceptor effect on amine and fluoride inhibitions documented above, we would offer the following observations. It has been established that amines bind as inhibitors to the higher $S$ states $\left(S_{2}\right.$ and $\left.S_{3}\right)$ $[15,16]$. It seems likely that the steady state concentrations of the higher $S$ states can be affected by the type of electron acceptor employed owing to back reactions between these $S$ states and the reducing side of PS II; Kok reported that the decay of the $S_{2}$ and $S_{3}$ states in flash experiments was 20-times faster in the absence of electron acceptors and attributed that result to back reactions of this type [32]. It is also known that the rate-limiting step in steady-state thylakoid membrane electron transport employing class I electron acceptors (e.g., $\mathrm{Fe}(\mathrm{CN})_{6}^{-3}$ ), is the reoxidation of the plastoquinone pool by the $b_{6}-f$ complex [33]. This is reflected in the control rates observed in our experiments, which are 320 and $270 \mu \mathrm{mol}$ oxygen per $\mathrm{mg} \mathrm{Chl}$ per $\mathrm{h}$ in the DCBQ and $\mathrm{Fe}(\mathrm{CN})_{6}^{-3}$ supported assays respectively (uncoupled with $10 \mu \mathrm{g}$ per ml gramicidin) under saturating illumination. Thus, it seems possible that the plastoquinone pool would be overreduced in the course of electron-transfer assays where $\mathrm{Fe}\left(\mathrm{CN}_{6}^{-3}\right.$ was used as the electron acceptor in place of DCBQ. Reduction of the plastoquinone pool would in turn promote back reactions to reduce the higher $S$ states and thus affect inhibitor binding. Conversely, since DCBQ accepts electrons close to the reducing side of PS II, its presence would intensify amine-induced inhibition by raising the steadystate concentrations of $S_{2}$ and $S_{3}$. Fluoride-induced inhibition is also enhanced by the presence of DCBQ. Although it has not yet been documented that fluoride binds preferentially to the higher S-states, if the explanation of the effect of the electron acceptor system on amine-induced inhibition given above is correct, then it is only reasonable to conclude that fluoride also binds preferentially to the higher S-states. 


\section{Discussion}

The results presented in this communication, along with our earlier data $[10,11]$ lead us to the following conclusions.

(1) The binding site for.chloride in the higher $S$ states of the oxygen-evolving complex is electrophilic, as evidenced by the ability of amine free bases and fluoride to compete with chloride for this binding site.

(2) Displacement of chloride from the higher $\mathrm{S}$ states of the oxygen-evolving complex by amine free bases is governed by the nucleophilicity of the amine (see Fig. 2). This finding reinforces our earlier hypothesis that the site of interaction between chloride and amines is a ligand site (or sites) on manganese in oxidation states higher than $\mathrm{Mn}(\mathrm{II})$.

(3) Conditions which affect reoxidation of the reducing side of PS II, and which must therefore also affect the distribution of higher $\mathrm{S}$ states affect the intensity of binding by amines and fluoride (see Figs. 7-9). From this finding and the data of Fig. 6, we conclude that amines and fluoride must compete for a chloride binding site(s) associated with higher $\mathrm{S}$ states.

(4) A second, chloride-insensitive site of nucleophilic attack is also present in the oxygen-evolving complex. This site is accessible only to ammonia, not to amines of larger size (see Table I). The most reasonable interpretation of this finding is that already proposed by Radmer [28], namely that the waterbinding site of the oxygen-evolving complex resides in a sterically hindered 'cleft' which prevents the binding of bulky nucleophiles (in the present case, amines larger than ammonia).

One consequence of our data arises from the results on the interaction of fluoride with the chloride binding site of the oxygen-evolving complex. It has been proposed that the role of activating anions in the oxygen-evolving reaction is to neutralize positive charges on proteins to produce an active conformation of the oxygen-evolving complex [7,8], and that this phenomenon is similar to the anion-induced activations of some enzymes $[34,35]$. For example, $\alpha$-amylase contains no redox active metals and is activated by chloride, bromide, iodide and nitrate with an order of effectiveness which is strikingly similar to that of the oxygenevolving complex [36]. There is one important difference between $\alpha$-amylase and the oxygenevolving complex, however. Fluoride neither activates $\boldsymbol{\alpha}$-amylase, nor does it compete with chloride for binding to the activator site [36]. We would also note that the competition between hydroxide ion and chloride documented in Ref. 34, proposed to reflect an essential protonation step in the oxygen-evolving reaction, might also reflect displacement of chloride by hydroxide from a metal-binding site. Such a displacement has been reported by Ikeda-Sato and Prince [37] for the iron atom in myeloperoxidase.

Others $[13,14]$ have used our proposals concerning the catalytic role of chloride in oxygen-evolution activity to construct elaborate models, which in one case (a paramagnetically inactive $S_{2}$ state) contradicts experimental results (the EPR multiline signal [19]). We prefer a simple model such as that we proposed earlier [11] as a schematic representation for a hypothetical interaction of chloride as a bridging ligand between manganese atoms. We would point out that a bridging ligand function is a reasonable explanation for the observation that large, soft nucleophiles (e.g., chloride, bromide and iodide) function as activators of oxygen evolution, whereas small, hard nucleophiles (amines, hydroxide and fluoride) are inhibitors when bound to the activator site. Alternatively, it is also possible that the oxygen-evolving complex is activated by the binding of soft anions to $\mathrm{Mn}$ atoms without the formation of ligand bridges; the binding of different ligands would affect the electronic structure of the manganese and might therefore be expected to alter the redox and catalytic properties of the metal. However, in the absence of more detailed information concerning the redox state, ligand geometry and the identity of the other ligands involved in the binding of manganese to the oxygen-evolving complex, we regard all conclusions regarding the nature of the chloride interaction with manganese to be tentative.

\section{Acknowledgements}

This research was supported by grants to C.F.Y. from the Competitive Research Grants Office of USDA (G-82-CRCR-1-1127) and the National Science Foundation (PCM82-14240). 


\section{References}

1 Arnon, D.I. and Whatley, F.R. (1959) Science 110, 554-556

2 Bové, J., Bové, M., Whatley, F.R. and Arnon, D.I. (1963) Z. Naturforsch. 18b, 683-688

3 Izawa, S., Heath, R. and Hind, G. (1969) Biochim. Biophys. Acta 180, 388-398

4 Kelly, P. and Izawa, S. (1974) Biochim. BIophys. Acta 502, $198-210$

5 Itoh, S., Yerkes, C.T., Koike, H., Robinson, H.H. and Crofts, A.R. (1984) Biochim. Biophys. Acta 766, 612-622

6 Theg, S., Jursinic, P. and Homann, P. (1984) Biochim. Biophys. Acta 766, 636-646

7 Johnson, J., Pfister, V. and Homann, P. (1983) Biochim. Biophys. Acta 723, 256-265

8 Homann, P., Johnson, J. and Pfister, V. (1983) in The Oxygen Evolving System of Photosynthesis (Inoue, $Y$., Crofts, A.R., Govindjee, Murata, N., Renger, G. and Satoh, K., eds.), pp. 283-292, Academic Press Japan, Tokyo

9 Wydryzynski, T, and Sauer, K. (1980) Biochim. Biophys. Acta 587, 56-70

10 Sandusky, P.O. and Yocum, C.F. (1983) FEBS Lett. 162, 339-343

11 Sandusky, P.O. and Yocum, C.F. (1984) Biochim. Biophys. Acta 766, 603-611

12 Amesz, J. (1983) Biochim. Biophys. Acta 726, 1-21

13 Critchley, C. and Sargeson, A. (1984) FEBS Lett. 177, 2-5

14 Critchley, C. (1985) Biochim. Biophys. Acta 811, 33-46

15 Velthuys, B.R. (1975) Biochim. Biophys. Acta 396, 392-401

16 Frasch, W. (1979) Ph.D. Dissertation, University of Kentucky, Lexington, KY

17 Ghanotakis, D.F., O'Malley, P.J., Babcock, G.T. and Yocum, C.F. (1983) in The Oxygen Evolving System of Photosynthesis (Inoue, Y., Crofts, A.R., Govindjee, Murata, N., Renger, G. and Satoh, K., eds.), pp. 91-101, Academic Press Japan, Tokyo

18 Ghanotakis, D.F., Topper, J.N. and Yocum, C.F. (1984) Biochim. Biophys. Acta 767, 524-531
19 Dismukes, G.C. and Siderer, Y. (1981) Proc. Natl. Acad. Sci. USA 78, 274-277

20 Dekker, J.P., Van Gorkom, H.J., Brok, M. and Ouwehand, L. (1984) Biochim. Biophys. Acta 764, 301-309

21 Goodin, D.B., Yachandra, V.K., Britt, R.D., Sauer, K. and Klein, M.P. (1984) Biochim. Biophys. Acta 767, 209-216

22 Sharp, R.R. and Yocum, C.F. (1980) Biochim. Biophys. Acta 592, 185-195

23 Berthold, D.A., Babcock, G.T., and Yocum, C.F. (1981) FEBS Lett. 134, 231-234

24 Ghanotakis, D.F. and Babcock, G.T. (1983) FEBS Lett. $153,231-234$

25 Robinson, S.J., DeRoo, C.S. and Yocum, C.F. (1982) Plant Physiol. 70, 154-162

26 Cornish-Bowden, A. (1974) Biochem. J. 137, 143-144

27 Segel, I. (1980) Enzyme Kinetics, Wiley Interscience, New York, NY

28 Radmer, R. and Ollinger, O. (1983) FEBS Lett. 152, 39-43

29 Handbook of Biochemistry (Sober, H.A., ed.), pp. J-69-74, 2nd Edn., Chemical Rubber Publishing Co., Cleveland, OH

30 Angellici, R. (1973) in Inorganic Biochemistry (Eichhorn, G., ed.), pp. 63-101, Elsevier, Amsterdam

31 Baianu, I.C., Critchley, C., Govindjee and Gutowsky, H.S. (1984) Proc. Natl. Acad. Sci. USA 81, 3713-3717

32 Joliot, P. and Kok, B. (1975) in Bioenergetics of Photosynthesis (Govindjee, ed.), pp. 387-412, Academic Press, New York, NY

33 Radmer, R. and Cheniae, G.M. (1974) in Primary Processes of Photosynthesis (Barber, J., ed.), pp. 303-348, Elsevier, Amsterdam

34 Homann, P. (1985) Biochim. Biophys. Acta 809, 311-319

35 Levitzki, A. and Steer, M. (1974) Eur. J. Biochem. 41, 171-180

36 Lifshitz, R. and Levitzki, A. (1976) Biochemistry 15, 1987-1993

37 Ikeda-Sato, T. and Prince, R. (1985) J. Biol. Chem. 260, 8301-8305 